\title{
Efficient Green Synthesis and Biological Evaluation of Thiadiazole Derivatives
}

\author{
Prem Shankar Mishra ${ }^{1(\mathbb{D})}$, Rakhi Mishra ${ }^{2(\mathbb{D})}$, Ram Ji Gupta ${ }^{1(\mathbb{D})}$, Rupa Mazumder ${ }^{2} \mathbb{( D}^{2}$, \\ Rishabha Malviya 1 ,*(D) \\ 1 Department of Pharmacy, School of Medical and Allied Sciences, Galgotias University, Greater Noida, U.P., India \\ 2 Pharmacy Institute, Noida Institute of Engineering and Technology, Greater Noida, U.P., India \\ * Correspondence: rishabhamalviya19@gmail.com;
}

Scopus Author ID 36542724200

Received: 10.11.2020; Revised: 14.01.2021; Accepted: 16.01.2021; Published: 20.01.2021

\begin{abstract}
Thiadiazole and its derivatives have been studied extensively because of their wide range of biological activity. Diverse biological activities, such as antibacterial, anti-inflammatory, and antiviral, have been associated with thiadiazole derivatives. These derivatives were explored by the in-silico method by using the docking model. Given research work aimed at improving thiadiazole yield and quality by using a green chemistry approach, and the synthesized compounds were screened for antibacterial activities. In the present work, some new thiadiazole ring containing compounds were synthesized, but the synthesis was carried out using green chemistry methods like microwave and ultrasonication techniques. Compounds were screened by spectral analysis, and further antimicrobial evaluation was also done. These derivatives were explored by the in-silico method by using the docking model. All the screened derivatives exhibited good results, especially the 3C compound, which showed the lowest binding energy with the receptor $(-7.449 \mathrm{Kcal} / \mathrm{mol})$. Research using the green chemistry approach gives the successful synthesis of thiadiazole derivatives with good yield in between $75-90 \%$. As compared to conventional synthesis methods, these methods require less time; the newly synthesized compounds also reflect moderate to promising antimicrobial activity against E.coli and P.aureginosa. All the selected derivatives were docked with the selected PDB code's active site and assessed for binding free energy and their interaction with the receptor. 3e compound showed maximum binding free energy $-7.449 \mathrm{Kcal} / \mathrm{mol}$.
\end{abstract}

Keywords: thiadiazole; green chemistry; conventional; microwave; ultrasonication; antimicrobial.

(C) 2020 by the authors. This article is an open-access article distributed under the terms and conditions of the Creative Commons Attribution (CC BY) license (https://creativecommons.org/licenses/by/4.0/).

\section{Introduction}

Thiadiazoles belong to five-membered nitrogen-sulfur ring system with two nitrogen and one sulfur atom and are widely present as a unit in the structure of various biologically active molecules and act as a useful intermediate in the synthesis of various important heterocycles [1]. Chemically Thiadiazole exist in four isomeric forms viz-1, 2, 3-thiadiazole; 1, 2, 5-thiadiazole; 1, 2, 4-thiadiazole and 1, 3, 4-thiadiazole [2]. Thiadiazole possesses sulfide linkage, which gives retaliate characteristic to thiadiazole; also, oxygen, nitrogen, and the presence of a sulfur atom affect the physical and chemical properties of thiadiazole [3]. Different drug classes like anti-inflammatory, antimicrobial, antiviral, antiepileptic, antitubercular agents contain thiadiazole nucleus as a building block in their chemical structure, giving the conclusion that thiadiazole and its derivatives have diverse potent activities and can be regarded as pharmacologically significant scaffolds [4]. In recent years research shows wide 
applications of thiadiazole and its derivatives such as antimicrobial [5] antituberculosis, anticonvulsants, anti-inflammatory, antihypertensive [6] antioxidant, human adenosine A3 antagonist[7], anticancer [8, 9], and antifungal activity [10]. Vit. B1 incorporates thiazolium ring showing the prominent role of thiadiazole in nature also [11].

While considering the synthesis, it is now challenging to find an approach that consists of environment-friendly chemical processes. Products require the development of novel and cost-effective methods that are pollution-free also.

Green chemistry is one of the significant and latest chemistry concepts that uses various principles, which causes a reduction in cost, time, use, or generation of hazardous substances in the process of chemical production [12]. In the present scenario, green chemistry techniques such as ultrasonic and microwave-assisted organic synthesis (MAOS) affect synthetic, medicinal chemistry widely and significantly by reducing time expense and enabling reproducible chemistry development with improvement in yield and quality of products[1314]. Thus one can conclude that green chemistry synthesis is an enabling technology for accelerating drug design, discovery, and development processes. Hence, this field has-evergrowing importance resulting in the development scores of thiadiazoles [15-17]. In the present research work, new thiadiazole derivatives were synthesized from thiosemicarbazide using green chemistry, an eco-friendly, nonhazardous, reproducible, and economical approach; furthermore, the structures of synthesized compounds were confirmed based on spectral data. Further, the synthesized compounds were tested for their antimicrobial activity. The structures of synthesized compounds were confirmed based on spectral data. The compounds were also tested for their antimicrobial activities by standard methods.

\section{Materials and Methods}

\subsection{Materials.}

The reaction was carried out with analytical reagent grade chemicals, which were commercially procured from various chemical units, and glasswares used were made of pyrex glass. Used solvent and reagents were of LR grade and were purified before use. 120-160 mesh silica gel $\mathrm{G}$ was obtained from E.Merck India Ltd., which was used for TLC analytical chromatography. The solvent system used was ethyl acetoacetate: petroleum ether (7:3). For vacuum filtration, ashless Whatman number 1 filter paper was used. Melting points were determined in an open glass capillary using melting point apparatus and are uncorrected. IR Spectra KBr) was recorded on FTIR Spectrophotometer (Shimadzu FTIR 84005, 4000-400 cm

${ }^{1}$ ). The electrospray mass spectra were recorded on a THERMO Finnigan LCQ Advantage max ion trap mass spectrometer. ${ }^{1} \mathrm{H}$ NMR was recorded on a Bruker DRX-300 MHz spectrometer in $\mathrm{CDCl}_{3}$ using TMS as an internal standard, with ${ }^{1} \mathrm{H}$ resonance frequency of $300 \mathrm{MHz}$. Chemical shift values are expressed in $\delta$ ppm. For antimicrobial activities, Minimum Inhibitory concentration (MIC) was found by using the serial dilution method.

\subsection{Synthesis of compounds.}

\subsubsection{General Method for Synthesis of thiosemicarbazide derivatives (1a-1e).}

Substituted aniline derivative was taken and was dissolved in ethanol $(95 \%, 50 \mathrm{ml})$ and ammonia solution $(20 \mathrm{ml})$. Then $20 \mathrm{ml}$ of carbon disulfide was added slowly to a solution of aniline derivatives with shaking. The resulting solution was allowed to stand for 1 hour. Then 
$0.1 \mathrm{M}$ sodium chloroacetate and $20 \mathrm{ml}$ of $50 \%$ hydrazine hydrate were added to the solution. The reaction mixture was warmed gently, filtered, and evaporated to half of its volume, and kept overnight. The solid thus obtained was filtered and purified by recrystallization from ethanol. Their characterization is given in table 1.

Spectral characterization of thiosemicarbazide derivatives are as follows:

1-phenyl thiosemicarbazide (1a)IR (KBr) v/cm-1(2a): $\mathrm{C}_{7} \mathrm{H}_{9} \mathrm{~N}_{3} \mathrm{~S}, 3005(\mathrm{C}-\mathrm{H}), 1625$ (C-C), 3234 (-N-H), 3230 (-N-H), 3222 (-N-H), 2563(-C-S); ${ }^{1}$ H NMR (400 MHz, DMSO-d6,

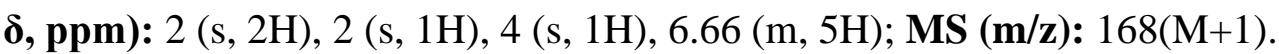

1- (3-nitro phenyl) thiosemicarbazide (1b): IR (KBr) v/cm-1: 3008 (C-H), 1622 (-C-C), 3214 (-N-H), 3250 (-N-H), 3123 (-N-H), $1496\left(\mathrm{NO}_{2}\right), 2632(-\mathrm{C}-\mathrm{S})$;1 H NMR(400 MHz, DMSO-d6, $\boldsymbol{\delta}$, ppm): 1.97 (s, 2H), 2 (s, 1H), 3.96 (s, 1H), 7.54 (d, 2H), 7.59 (s, 1H); MS (m/z): $212(\mathrm{M}+1)$.

$\checkmark$ 1- (3-methyl phenyl) thiosemicarbazide (1c): IR (KBr) v/cm-1: 3000 (C-H), 1619 (-CC), 3200 (-N-H), 3247 (-N-H), 3103 (-N-H) , 2632(-C-S); ${ }^{1}$ H-NMR(400 MHz, DMSO-d6, $\boldsymbol{\delta}$, ppm): 2.33 (s, 2H), 2.38 (s, 1H), $4.08(\mathrm{~s}, 1 \mathrm{H}), 2.35$ (s,3H), $6.46(\mathrm{~s}, 2 \mathrm{H}) ; \mathbf{M S}(\mathbf{m} / \mathbf{z}): 182(\mathrm{M}+1)$ $\checkmark$ 1- (3-methoxy phenyl) thiosemicarbazide (1d): IR (KBr) v/cm-1: 3012(C-H), 1600 (C-C), 3226 (-N-H), 3240 (-N-H), 3100 (-N-H) , 3000(-C-H), 2632(-C-S); ${ }^{1}$ H NMR(400 MHz, DMSO-d6, $\delta$, ppm): 2.12 (s, 2H), 2 (s, 1H), 3.89 (s, 1H), 3.73 (s, 3H), 7.04 (d, 2H), 6.22 (s, 1H); MS (m/z): $198(\mathrm{M}+1)$.

$\checkmark$ 1- (3-chloro phenyl) thiosemicarbazide (1e): IR (KBr) v/cm-13022(C-H), 1622 (-C-C), 3232 (-N-H), 3220 (-N-H), 3100 (-N-H), 2632(-C-S), 740 (-Cl) ; ${ }^{1}$ H NMR(400 MHz, DMSOd6, $\boldsymbol{\delta}, \mathbf{p p m}): 2.22$ (s, 2H), $2.11(\mathrm{~s}, 1 \mathrm{H}), 3.79$ (s, 1H), 6.64 (d, 2H); MS (m/z): $202(\mathrm{M}+1)$.

2.2.2. Synthesis of Thiadiazole derivatives (2a-2e) and (3a-3e).

\subsubsection{Microwave irradiation method (2a-2e).}

Substituted thiosemicarbazide (0.10M), substituted benzoic acid (0.01M). Phosphorous oxychloride $(25 \mathrm{ml})$ were taken into a beaker and dissolved in a minor quantity of dimethylformamide (10 ml) [18]. To this solution, concentrated sulphuric acid (10 drops) was added while stirring. A funnel was hanged in the beaker and covered with a watch glass. The reaction mixture was subjected to microwave irradiation at $300 \mathrm{~W}$ for $3 \mathrm{~min}$, with a pulse rate of $30 \mathrm{sec}$ in a laboratory microwave oven. Allow the flask's contents to attain room temperature, and pour it directly into a beaker having $30 \mathrm{ml}$ of cold water and stirred vigorously [19]. The crude product was filtered onto a Buchner funnel using suction and washed with small portions of cold water, and dried. It was purified by recrystallization from hot alcohol. Their characterization data is given in Table 2.

\subsubsection{Ultrasonic irradiation method (3a-3e).}

Substituted thiosemicarbazide $(0.05 \mathrm{M})$, substituted benzoic acid $(0.01 \mathrm{M})$, and concentrated sulphuric acid $(5 \mathrm{~mL})$ was taken in a beaker $(50 \mathrm{ml})$. The mixture was subjected to ultrasonic irradiation for $20 \mathrm{~min}$ at room temperature [20,21]. Furthermore, the reaction mixture was poured over ice-cooled water. The crude product was filtered and crystallized with DMF. The structure of synthesized compounds (3a-3e) is shown in fig 1 . Their characterization data is given in Table 3.

Spectral characterization of thiadiazole derivatives are as follows: 
4-(5-(phenylamino)-1,3,4-thiadiazol-2-yl) benzoic acid(3a): IR (KBr, $\left.\mathbf{~ c m}^{-1}\right) 3379$ (N$\mathrm{H}$ Amines), $3073(\mathrm{C}-\mathrm{H}$ Ar), $2225(\mathrm{C}=\mathrm{N}$ Ar), 2952 (hydrogen bonded acids) ,1725 (C=O Acids), 2625 (O-H Acids), 1590 (C=C Ar); ${ }^{1} \mathbf{H}$ NMR: $\left(\mathbf{C D C l}_{3}, \boldsymbol{\delta}, \mathbf{p p m}\right): 4$ (s, 1H,NH of thiadiazole), 7.01 (s, 2H, Ar-(C-H)), 6.5 (s, 3H, Ar C-H), 11 (s, 1H,OH). MS (m/z): 298.06 $(\mathrm{M}+1)$.

$\checkmark$ 4-(5-(3 nitro phenylamino)-1,3,4-thiadiazol-2-yl) benzoic $\operatorname{acid}(3 \mathrm{~b}): \operatorname{IR}\left(\mathrm{KBr}, \mathrm{cm}^{-1}\right)$ : 3408 (N-H Amines), 3342 (C-H Ar), 2300 (C=N Ar), 1665(C=C Ar), 1689 (C=O Acids), 1400 (C-N Ar), $1570\left(\mathrm{NO}_{2}\right)$; ${ }^{1} \mathbf{H}$ NMR:(CDCl $\left.\mathbf{3}, \boldsymbol{\delta}, \mathbf{p p m}\right): 3.97$ (s, 1HNH of thiadiazole), 7.39 (s, 2H, Ar-(C-H)), 7.66 (s, 3H, Ar C-H), 11.01 (s, 1H,OH) MS (m/z): $343(\mathrm{M}+1)$.

$\checkmark$ 4-(5-(3 methyl phenylamino)-1,3,4-thiadiazol-2-yl) benzoic $\operatorname{acid}(3 \mathrm{c}): \operatorname{IR}\left(\mathrm{KBr}, \mathrm{cm}^{-1}\right)$ : 3453 (N-H Amines), 3250 (C-H Ar), 2175 (C=N Ar),1566 (C=C Ar), 1427(NO2 Nitro compound), 1295 (C-N Ar), ${ }^{1} \mathbf{H}$ NMR:(CDCl 3 , $\boldsymbol{\delta}$, ppm): 2.35 (s, 3H of CH3), 4.0 (s, 1H,NH of thiadiazole), 7.43 (s, 2H, Ar-(C-H)), 6.27 (s, 3H, Ar C-H), 10.94 (s, 1H,OH)MS (m/z): 312 $(\mathrm{M}+1)$.

$\checkmark$ 4-(5-(3 methoxy phenylamino)-1,3,4-thiadiazol-2-yl) benzoic acid(3d): IR (KBr, cm1): 3400 (N-H Amines), 3212 (C-H Ar), 2155 (C=N Ar), 1560 (C=C Ar), 2850(C-H cmethoxy), 1740 (O-C str), 1288 (C-N Ar), ${ }_{1}^{1} \mathbf{H}$ NMR:(CDCl $\left.\mathbf{3}, \boldsymbol{\delta}, \mathbf{p p m}\right): 5.97$ (s, 3H of CH3), 4.0 (s, 1H,NH of thiadiazole), 8.19 (s, 2H, Ar-(C-H)), 6.90 (s, 3H, Ar C-H), 11.93 (s, 1H,OH) MS (m/z): 328 $(\mathrm{M}+1)$.

$\checkmark$ 4-(5-(3 chloro phenylamino)-1,3,4-thiadiazol-2-yl) benzoic acid(3e): IR (KBr, $\left.\mathbf{c m}^{-1}\right)$ 3419 (N-H Amines), 3100 (C-H Ar), 2917 (C-H Ar), 2113 (C=NAr), 1595 (C=C Ar), 723 (C$\mathrm{Cl}), 1339$ (C-N Ar), ${ }^{1} \mathbf{H}$ NMR:(CDCl $\left., \boldsymbol{\delta}, \mathbf{p p m}\right): 4.0$ (s, 1H,NH of thiadiazole), 7.43 (s, 3H, Ar-H)), 8.19 (s, 1H, Ar C-H), 11 (s, 1H,OH). 2.34 ; MS (m/z) :332 (M+1)

\subsubsection{Antibacterial activity.}

\subsubsection{Material and methods.}

The microbiological testing of the synthesized compounds was done by the agar well diffusion method. Ampicillin was used as standard drugs [22]. Nutrient agar media were used for the purpose, which contains the constituents, as presented in table 1.

Table 1. Constituents of agar medium.

\begin{tabular}{l|l|l} 
S. No. & Constituents & Quantity required \\
\hline 1. & Peptic digest & $5 \mathrm{gm} / \mathrm{litre}$ \\
\hline 2 & Yeast Extract & $1.5 \mathrm{gm} / \mathrm{litre}$ \\
\hline 3 & Beef Extract & $1.5 \mathrm{gm} / \mathrm{litre}$ \\
\hline 4 & Sodium chloride & $5 \mathrm{gm} / \mathrm{litre}$ \\
\hline 5 & Agar & $15 \mathrm{gm} / \mathrm{litre}$ \\
\hline 6 & Distilled Water q.s. & 1 litre
\end{tabular}

2.2.4. Experimental procedures.

The Agar-diffusion method was used for the determination of the preliminary antibacterial activities. The agar well diffusion test was performed using nutrient agar medium, and the medium was autoclaved at $15 \mathrm{lbs}$ pressure $\left(121^{\circ} \mathrm{C}\right)$ for $15 \mathrm{~min}$ then was immediately cooled to $50-55{ }^{\circ} \mathrm{C}$ in a water bath after removing it from the autoclave [23-26]. The cooling medium was poured into sterile Petri plates to a uniform depth of $4 \mathrm{~mm}$; this is equivalent to approximately $40 \mathrm{ml}$ in a $90 \mathrm{~mm}$ plate. After solidification of the agar medium, culture was inoculated into the medium. All of the works were performed in a laminar flow; within 15 
minutes of adjusting the inoculums' density, a sterile cotton swab was dipped into the standardized bacterial suspension or inoculated with $1 \mathrm{~mL}$ organism suspension [27]. The sterile swab was used on the nutrient agar medium's surface to ensure an even distribution of the inoculums. The plates were undisturbed for 3 to 5 minutes to ensure excess moisture absorption [28]. A sterilized $7 \mathrm{~mm}$ cork borer was used to make agar wells. The concentrations of the 500 and $600 \mu \mathrm{g} / \mathrm{ml}$ of the diluted test compound stock solutions were placed into each well and $100 \%$ DMSO as a control.

\section{Results and Discussion}

Synthesis of Thiadiazole derivatives using a green chemistry approach proved to be a good technique for maximal yield with cost-effective and less time consumption. By following the microwave irradiation and ultrasonication technique, derivatives are obtained in good yield ranging from 60-90\%. While comparing the yield of two techniques for synthesis of compounds, it has been found that the microwave irradiation method gives a better yield ranging from $85-90 \%$ as by use of ultrasonic irradiation method yield ranges from $75-80 \%$. Structures of the synthesized substituted thiadiazole were confirmed from their respective IR, ${ }^{1} \mathrm{H}$ - NMR studies.

Thiadiazole based heterocyclic derivatives were also found to have encouraging antimicrobial activity [29-33]. Some are promising and need to be further investigated to get better agents. The antimicrobial screening observed that all the compounds exhibited activity against all the organisms employed. Among all synthesized five compounds, 2c, 2d, 3c, 3d show good antibacterial activity against $E$. coli and $P$. aeruginosa gram-negative bacteria and shows mild to moderate activity compared with reference compound ampicillin. Rank score and physicochemical properties of synthesized ligands are shown in Fig 2. Docking study of all five compounds against $E$. coli is shown in Fig 3. Among all docked compounds, 3e was found to be the most potent pose of which is shown in Fig 4. Docking of compounds is also done on $P$. aeruginosa, as shown in Fig 5. As we consider all results obtained from antibacterial tests together, we can say that entire compounds tested are active antimicrobial in nature.

Table 2. Physicochemical data of substituted thiosemicarbazides.

\begin{tabular}{l|c|c|c|c|c|c|c} 
S. No. & $\begin{array}{c}\text { Code } \\
\text { no. }\end{array}$ & $\mathbf{R}$ & $\begin{array}{c}\text { Molecular } \\
\text { Formula }\end{array}$ & M.W. & Rf value & $\begin{array}{c}(\%) \\
\text { Yield }\end{array}$ & M.P. $\left({ }^{\circ} \mathbf{C}\right)$ \\
\hline 1. & $1 \mathrm{a}$ & $\mathrm{H}$ & $\mathrm{C}_{7} \mathrm{H}_{9} \mathrm{~N}_{3} \mathrm{~S}$ & 167.2 & 0.74 & 82 & 230 \\
\hline 2. & $1 \mathrm{~b}$ & 3-nitro & $\mathrm{C}_{7} \mathrm{H}_{8} \mathrm{~N}_{4} \mathrm{O}_{2} \mathrm{~S}$ & 212 & 0.94 & 81.34 & 234 \\
\hline 3. & $1 \mathrm{c}$ & 3-Methyl & $\mathrm{C}_{8} \mathrm{H}_{11} \mathrm{~N}_{3} \mathrm{~S}$ & 181 & 0.58 & 82.32 & 237 \\
\hline 4. & $1 \mathrm{~d}$ & 3-methoxy & $\mathrm{C}_{8} \mathrm{H}_{11} \mathrm{~N}_{3} \mathrm{OS}$ & 197 & 0.73 & 86.50 & 238 \\
\hline 5. & 1e & 3-chloro & $\mathrm{C}_{7} \mathrm{H}_{8} \mathrm{ClN}_{3} \mathrm{~S}$ & 201 & 0.59 & 87.57 & 241
\end{tabular}

Table 3. Physicochemical data for the newly synthesized thiadiazole compounds (microwave irradiation).

\begin{tabular}{l|c|c|c|c|c|c|c|c} 
S. No. & $\begin{array}{c}\text { Code } \\
\text { no. }\end{array}$ & $\mathbf{R}$ & Molecular formula & M.W. & $\mathbf{R}_{\mathbf{f}}$ value & $\begin{array}{c}(\boldsymbol{\%}) \\
\text { yield }\end{array}$ & M.P $\left({ }^{\circ} \mathbf{C}\right)$ \\
\hline 1. & $2 \mathrm{a}$ & $\mathrm{H}$ & $\mathrm{H}$ & $\mathrm{C}_{15} \mathrm{H}_{11} \mathrm{~N}_{3} \mathrm{O}_{2} \mathrm{~S}$ & 297 & 0.72 & 86.00 & 321 \\
\hline 2. & $2 \mathrm{~b}$ & 3-nitro & $\mathrm{H}$ & $\mathrm{C}_{15} \mathrm{H}_{10} \mathrm{~N}_{4} \mathrm{O}_{4} \mathrm{~S}$ & 342 & 0.86 & 90.09 & 330 \\
\hline 3. & $2 \mathrm{c}$ & 3-methyl & $\mathrm{H}$ & $\mathrm{C}_{16} \mathrm{H}_{13} \mathrm{~N}_{3} \mathrm{O}_{2} \mathrm{~S}$ & 311 & 0.76 & 85.00 & 340 \\
\hline 4. & $2 \mathrm{~d}$ & 3-methoxy & $\mathrm{H}$ & $\mathrm{C}_{16} \mathrm{H}_{13} \mathrm{~N}_{3} \mathrm{O}_{3} \mathrm{~S}$ & 327 & 0.82 & 91.90 & 348 \\
\hline 5. & $2 \mathrm{e}$ & 3-chloro & $\mathrm{H}$ & $\mathrm{C}_{15} \mathrm{H}_{10} \mathrm{ClN}_{3} \mathrm{O}_{2} \mathrm{~S}$ & 331 & 0.81 & 86.00 & 346
\end{tabular}

Table 2 showed physicochemical characteristics of substituted thiosemicarbazides, while Table 3 showed physicochemical characteristics of substituted thiosemicarbazides.

Table 4 showed the physicochemical characteristics of the newly synthesized Thiadiazole compounds (ultrasonic irradiation). 
Table 4. Physicochemical data for the newly synthesized Thiadiazole compounds (ultrasonic irradiation).

\begin{tabular}{l|c|c|c|c|c|c|c|c} 
S. No. & $\begin{array}{c}\text { Code } \\
\text { no. }\end{array}$ & $\mathbf{R}$ & Molecular Formula & M.W. & Rf value & $\begin{array}{c}(\%) \\
\text { yield }\end{array}$ & M.P $\left({ }^{\circ} \mathbf{C}\right)$ \\
\hline 1. & $3 \mathrm{a}$ & $\mathrm{H}$ & $\mathrm{H}$ & $\mathrm{C}_{15} \mathrm{H}_{11} \mathrm{~N}_{3} \mathrm{O}_{2} \mathrm{~S}$ & 297 & 0.75 & 76.00 & 322 \\
\hline 2. & $3 \mathrm{~b}$ & 3-nitro & $\mathrm{H}$ & $\mathrm{C}_{15} \mathrm{H}_{10} \mathrm{~N}_{4} \mathrm{O}_{4} \mathrm{~S}$ & 342 & 0.83 & 72.00 & 341 \\
\hline 3. & $3 \mathrm{c}$ & 3-methyl & $\mathrm{H}$ & $\mathrm{C}_{16} \mathrm{H}_{13} \mathrm{~N}_{3} \mathrm{O}_{2} \mathrm{~S}$ & 311 & 0.77 & 74.00 & 340 \\
\hline 4. & $3 \mathrm{~d}$ & 3-methoxy & $\mathrm{H}$ & $\mathrm{C}_{16} \mathrm{H}_{13} \mathrm{~N}_{3} \mathrm{O}_{3} \mathrm{~S}$ & 327 & 0.84 & 75.90 & 348 \\
\hline 5. & $3 \mathrm{e}$ & 3-chloro & $\mathrm{H}$ & $\mathrm{C}_{15} \mathrm{H}_{10} \mathrm{ClN}_{3} \mathrm{O}_{2} \mathrm{~S}$ & 331 & 0.83 & 76.00 & 347
\end{tabular}

Table 5 showed the data obtained from the antibacetrria activity of synthesized compounds.

Table 5. Antibacterial activity data of synthesized compounds.

\begin{tabular}{|c|c|c|c|c|}
\hline S.No. & Compounds & $\begin{array}{c}\text { Concentration } \\
(\mu \mathrm{g} / \mathrm{ml})\end{array}$ & E. coli & P. aureginosa \\
\hline \multirow[t]{2}{*}{1.} & \multirow[t]{2}{*}{$2 \mathrm{a}$} & 500 & $10.3 \pm 0.38$ & $13.3 \pm 0.12$ \\
\hline & & 600 & $12.8 \pm 0.15$ & $13.9 \pm 0.82$ \\
\hline \multirow[t]{2}{*}{2.} & \multirow[t]{2}{*}{$2 b$} & 500 & $12.7 \pm 0.33$ & $9 \pm 0.99$ \\
\hline & & 600 & $12.8 \pm 0.16$ & $10.7 \pm 0.33$ \\
\hline \multirow[t]{2}{*}{3.} & \multirow[t]{2}{*}{$2 \mathrm{c}$} & 500 & $16.3 \pm 0.45$ & $14.2 \pm 0.77$ \\
\hline & & 600 & $17.2 \pm 0.33$ & $14.9 \pm 00.33$ \\
\hline \multirow[t]{2}{*}{4.} & \multirow[t]{2}{*}{$2 \mathrm{~d}$} & 500 & $17 \pm 0.55$ & $16.7 \pm 0.22$ \\
\hline & & 600 & $17.9 \pm 0.78$ & $17.8 \pm 0.55$ \\
\hline \multirow[t]{2}{*}{5.} & \multirow[t]{2}{*}{$2 \mathrm{e}$} & 500 & $10.1 \pm 0.99$ & $12.6 \pm 0.76$ \\
\hline & & 600 & $11.4 \pm 0.33$ & $12.9 \pm 0.90$ \\
\hline \multirow[t]{2}{*}{6.} & \multirow[t]{2}{*}{$3 a$} & 500 & $11 \pm 0.45$ & $11.7 \pm 0.12$ \\
\hline & & 600 & $12.9 \pm 0.74$ & $11.8 \pm 0.45$ \\
\hline \multirow[t]{2}{*}{7.} & \multirow[t]{2}{*}{$3 b$} & 500 & $12 \pm 0.45$ & $12.7 \pm 0.32$ \\
\hline & & 600 & $12.9 \pm 0.65$ & $12.8 \pm 0.55$ \\
\hline \multirow[t]{2}{*}{8.} & \multirow[t]{2}{*}{$3 c$} & 500 & $16 \pm 0.50$ & $17.7 \pm 0.12$ \\
\hline & & 600 & $16.9 \pm 0.68$ & $17.8 \pm 0.54$ \\
\hline \multirow[t]{2}{*}{9.} & \multirow[t]{2}{*}{$3 d$} & 500 & $16 \pm 0.56$ & $15.7 \pm 0.14$ \\
\hline & & 600 & $16.9 \pm 0.63$ & $16.8 \pm 0.35$ \\
\hline \multirow[t]{2}{*}{10.} & \multirow[t]{2}{*}{$3 e$} & 500 & $10 \pm 0.45$ & $10.7 \pm 0.26$ \\
\hline & & 600 & $10.9 \pm 0.72$ & $10.8 \pm 0.45$ \\
\hline 11. & Ampicillin & 500 & $\begin{array}{l}19.0 \pm 0.35 \\
17.9 \pm 0.42\end{array}$ & $\begin{array}{l}21.7 \pm 0.12 \\
17.8 \pm 0.45\end{array}$ \\
\hline
\end{tabular}

\subsection{Docking study result.}

All the selected derivatives were docked with active sites of selected PDB code and assessed for binding free energy and their interaction with the receptor. Table 6 concluded the binding free energy in $\mathrm{Kcal} / \mathrm{mole}$. The synthesized derivatives showed good binding energy with the selected receptor (PDB ID: 1X7V). Among these, 3e compounds showed maximum binding free energy $-7.449 \mathrm{Kcal} / \mathrm{mol}$.

Table 6. Summarize the binding free energy in Kcal/mole and the synthesized derivatives with good binding energy with the selected receptor.

\begin{tabular}{l|l|l|l|l} 
S. No. & Compound & Slog P & TPSA & LF V score \\
\hline 1 & $3 \mathrm{a}$ & 3.6 & 77.9 & -6.968 \\
\hline 2 & $3 \mathrm{~b}$ & 3.4 & 123.8 & -6.848 \\
\hline 3 & $3 \mathrm{c}$ & 4 & 77.9 & -6.334 \\
\hline 4 & $3 \mathrm{~d}$ & 3.7 & 87.2 & -7.23 \\
\hline 5 & $3 \mathrm{e}$ & 4.3 & 77.9 & -7.449
\end{tabular}

3.2. Docking study on PDB ID 1J2R (E. coli) and Pseudomonas aeruginosa PDB ID (1X7V).

Figure 1 shows the structure of the compound prepared by the ultrasonication method. 
3a)<smiles>CC(C)(C)c1ccc(-c2nnc(Nc3ccccc3)s2)cc1</smiles>

4-(5-(phenylamino)-1,3,4-thiadiazol-2-yl)benzoic acid compound with ethane (1:1)

3b)<smiles>O=C(O)c1ccc(-c2nnc(Nc3cccc([N+](=O)[O-])c3)s2)cc1</smiles>

4-(5-((3-nitrophenyl)amino)-1,3,4-thiadiazol-2-yl)benzoic acid

3c)

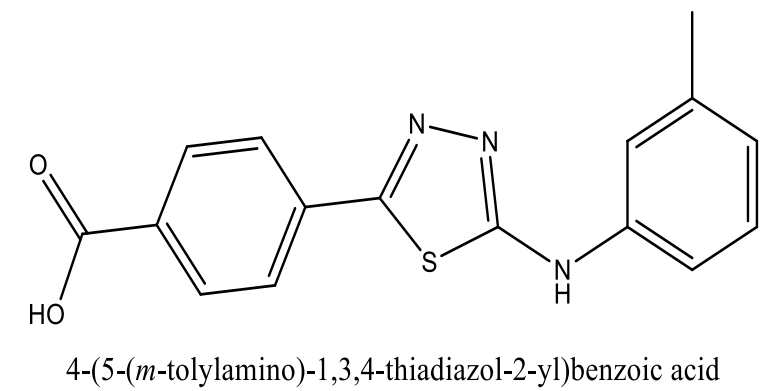

3d)

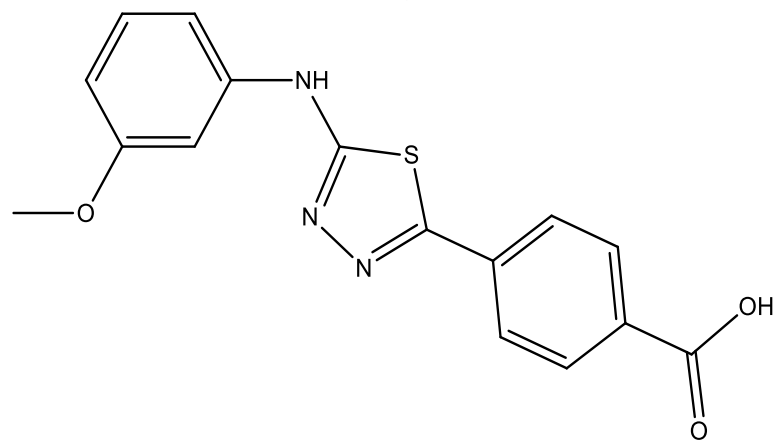

4-(5-((3-methoxyphenyl)amino)-1,3,4-thiadiazol-2-yl)benzoic acid

$3 e)$

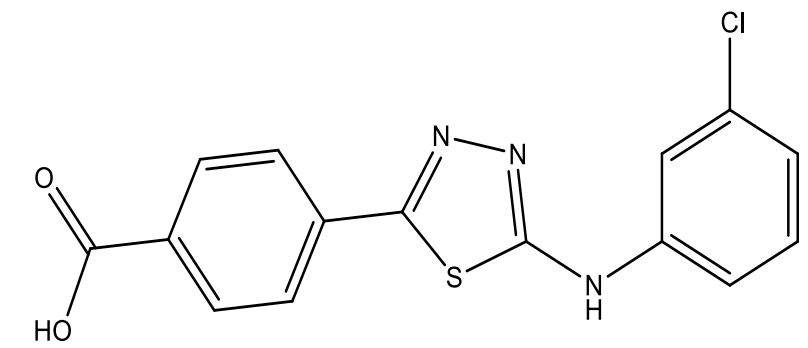

4-(5-((3-chlorophenyl)amino)-1,3,4-thiadiazol-2-yl)benzoic acid

Figure 1. Structure of synthesized compounds 3a-3e (by ultrasonication method). 


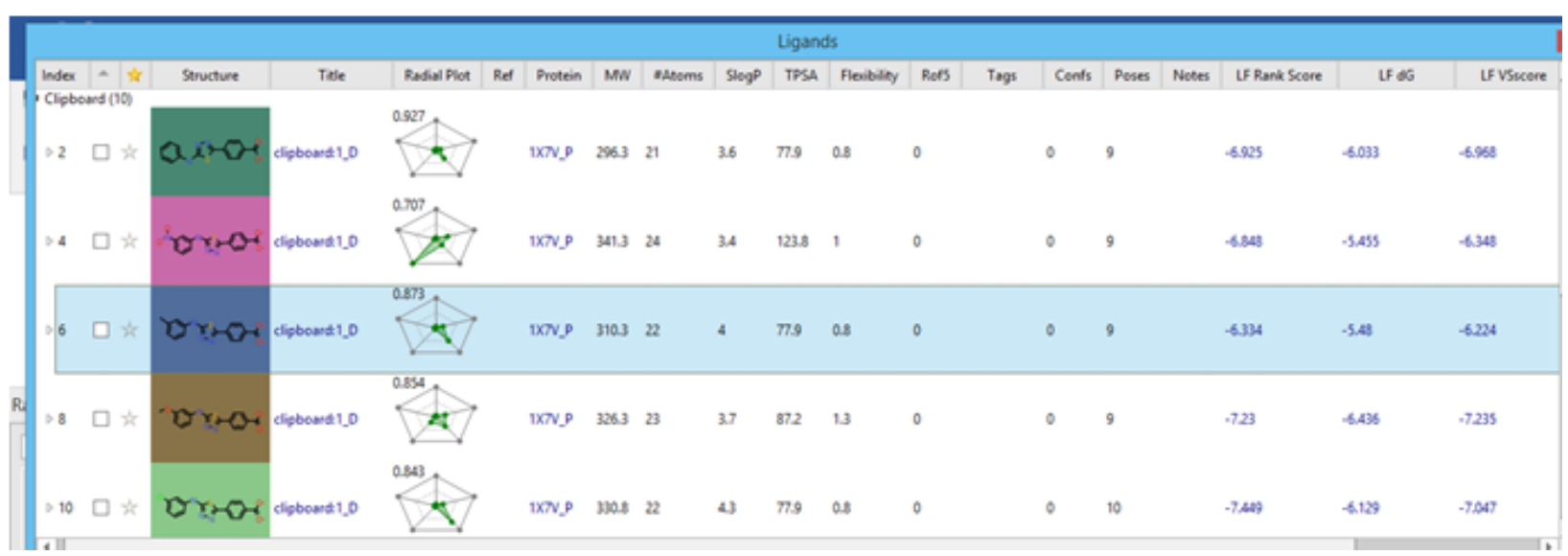

Figure 2. Showing rank score and physicochemical properties of synthesized ligands for docking study.

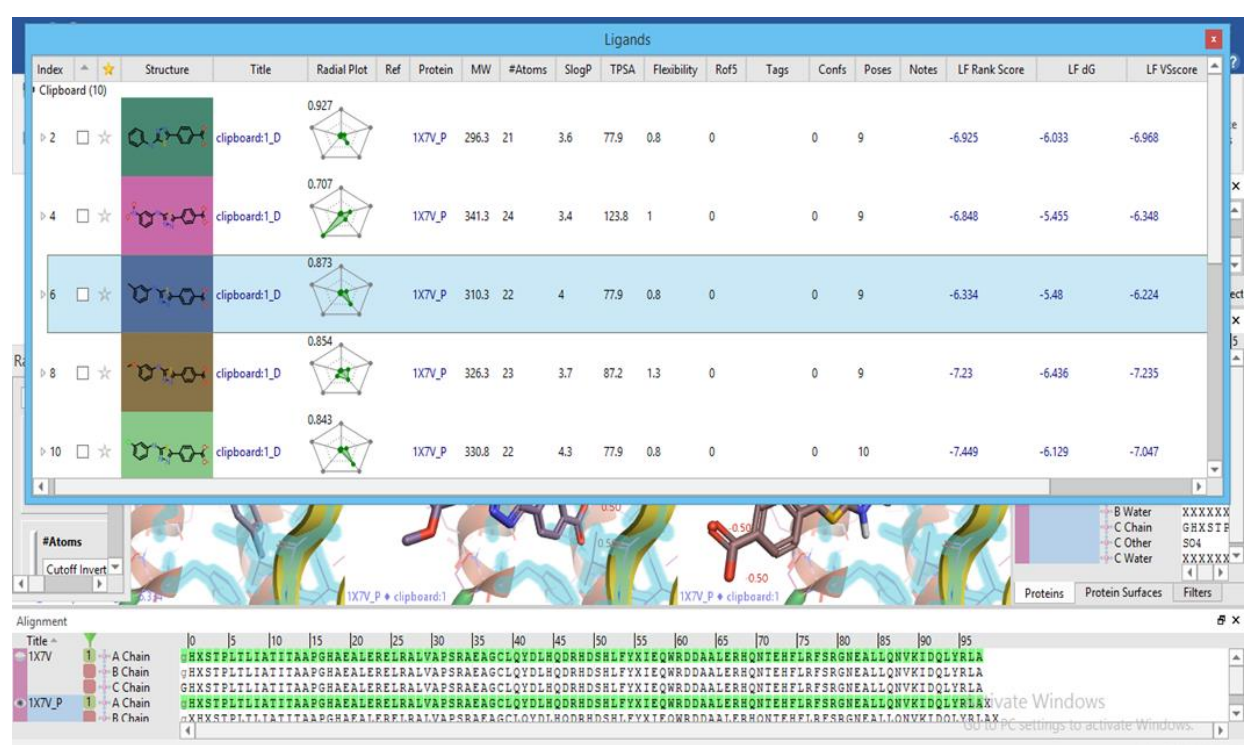

Figure 3. Showing synthesized drug-receptor interactions with PDB ID 1X7V with their amino acid sequences.

Figure 2 shows the rank score and physicochemical properties of synthesized ligands for docking study. Figure 3 shows synthesized drug-receptor interactions with PDB ID 1X7V with their amino acid sequences.

In this series, the compound $3 \mathrm{e}$ is the most active compound against $P$. aeruginosa based on docking score energies and antimicrobial evaluation.

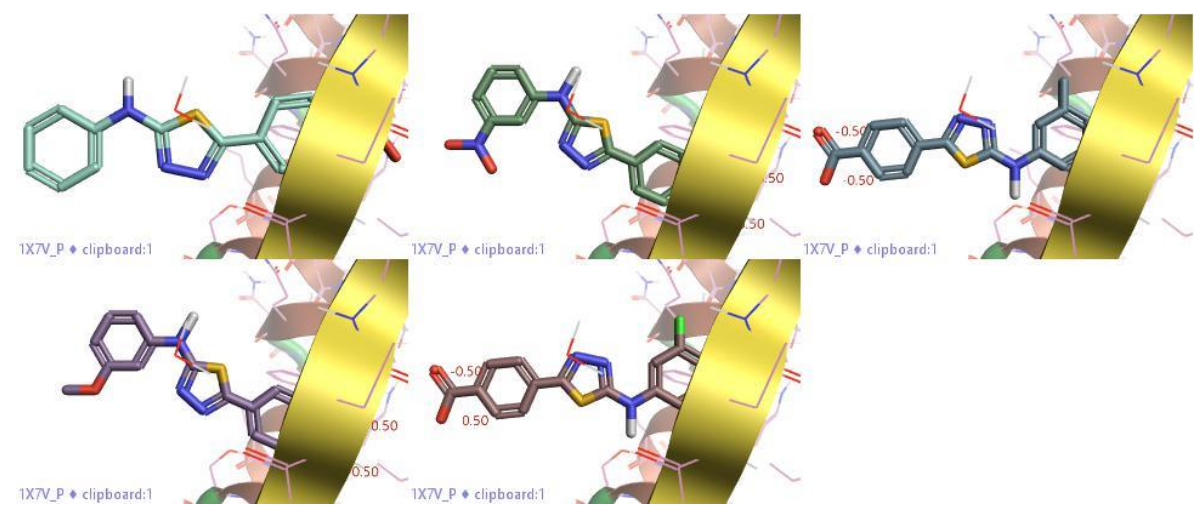

Figure 4. In silico screening (Docking) study of compounds (3a-3e) on E. Coli (PDB ID - IX7V).

Figure 4 shows in silico screening (Docking) study of compounds (3a-3e) on E. coli (PDB ID -1X7V). 
Most active compound: Figure 5 shows the docking pose of compound 3e with E. Coli (PDB ID -1X7V), and figure 6 shows in silico screening (Docking) study of compounds (3a3e) on Pseudomonas aeruginosa (PDB ID -1X7V).

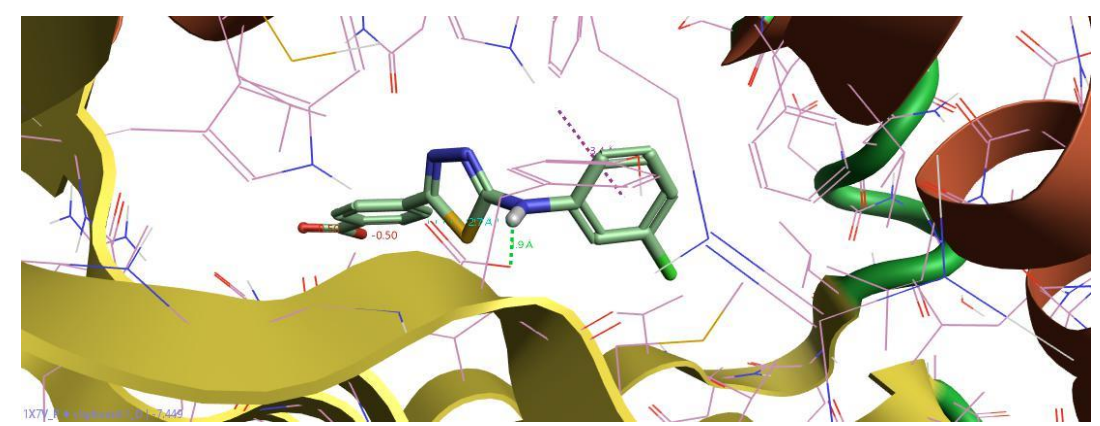

Figure 5. Most promising docking pose of compound 3e with E. Coli (PDB ID - IX7V).

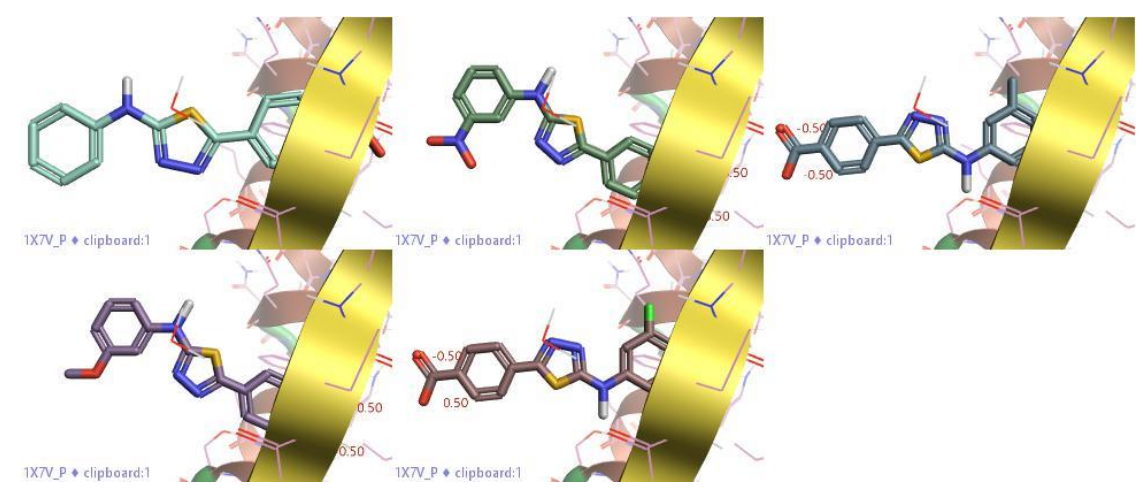

Figure 6. In silico screening (Docking) study of compounds (3a-3e) on Pseudomonas aeruginosa $(P D B I D-1 X 7 V)$.

\section{Conclusions}

Results and practical yield obtained using the green chemistry approach in the synthesis of thiadiazole derivatives conclude that conventional methods of synthesis can be substituted by ultrasonic and microwave irradiation methods (Green chemistry methods). By the methods of microwave and ultrasonic irradiation, thiadiazole derivatives are synthesized with good yield. Also, there is saving of time and chemicals. Thus Green chemistry methods can be used in the future in place of conventional synthetic methods. The compound $3 \mathrm{e}$ was the most active compound against $P$. aeruginosa based on docking score energies and antimicrobial evaluation.

\section{Funding}

This research received no external funding.

\section{Acknowledgments}

We gratefully acknowledge the management of Noida Institute of Engineering and Technology, Greater Noida, for full support while doing research work and using different instruments to fulfill all required laboratory conditions.

\section{Conflicts of Interest}

The authors declare no conflict of interest. 


\section{References}

1. Serban, G.; Stanasel, O.; Serban, E.; Bota, S. 2-Amino-1,3,4-thiadiazole as a potential scaffold for promising antimicrobial agents. Drug design, development and therapy 2018, 12, 1545-1566, https://doi.org/10.2147/DDDT.S155958.

2. Siddiqui, N.; Ahuja, P.; Ahsan, W.; Pandeya, S.N.; Alam, S.M. Thiadiazoles: Progress report on biological activities. J ChemPharm 2009, 1, 19-30.

3. Bhat, A.R.; Tazeem; Azam, A.; Choi, I.; Athar, F. 3-(1,3,4-Thiadiazole-2-yl)quinoline derivatives: Synthesis, characterization and antimicrobial activity. European Journal of Medicinal Chemistry 2011, 46, 3158-3166, https://doi.org/10.1016/j.ejmech.2011.04.013.

4. Jain, A.; Sharma, Simant.; Vaidya, A.; Ravichandran, V.; Agarwal, R. A. 1,3,4-Thiadiazole and its Derivatives: A Review on Recent Progress in Biological Activities. Chem Biol Drug Des 2013, 81, 557576.

5. Chapleo, C.B.; Myers, M.; Myers, P.L.; Saville, J.F.; Smith, A.C.; Stillings, M.R.; Tulloch, I.F.; Walter, D.S.; Welbourn, A.P. Substituted 1,3,4-thiadiazoles with anticonvulsant activity. 1. Hydrazines. J Med Chem 1986, 29, 2273-2280, https://doi.org/10.1021/jm00161a024.

6. Jung, K.-Y.; Kim, S.-K.; Gao, Z.-G.; Gross, A.S.; Melman, N.; Jacobson, K.A.; Kim, Y.-C. Structureactivity relationships of thiazole and thiadiazole derivatives as potent and selective human adenosine A3 receptor antagonists. Bioorganic \& Medicinal Chemistry 2004, 12, 613-623, https://doi.org/10.1016/j.bmc.2003.10.041.

7. Shen, L.-H.; Li, H.-Y.; Shang, H.-X.; Tian, S.-T.; Lai, Y.-S.; Liu, L.-J. Synthesis and cytotoxic evaluation of new colchicine derivatives bearing 1,3,4-thiadiazole moieties. Chinese Chemical Letters 2013, 24, 299 302,https://doi.org/10.1016/j.cclet.2013.01.052.

8. Juszczak, M.; Matysiak, J.; Szeliga, M.; Pożarowski, P.; Niewiadomy, A.; Albrecht, J.; Rzeski, W. 2-Amino1,3,4-thiadiazole derivative (FABT) inhibits the extracellular signal-regulated kinase pathway and induces cell cycle arrest in human non-small lung carcinoma cells. Bioorg Med Chem Lett 2012, 22, 54665469,https://doi.org/10.1016/j.bmcl.2012.07.036.

9. Kumar, K.; Govindappa, V.K.; Nagamallu, R. Thiadiazoles: Molecules Of Diverse Applications -A Review. International Journal of PharmTech Research 2013, 5, 239-248.

10. Raj, M.; Patel, H.V.; Raj, L.M.; Patel, N.K. Synthesis and biological evaluation of some new 1,3,4thiadiazole derivatives for their antimicrobial activities. Int J Pharm Chem Bio Sci 2013, 3, 814-819.

11. Sharma, S.; Gangal, S.; Rauf, A. Green chemistry approach to the sustainable advancement to the synthesis of heterocyclic chemistry. Rasayan Journal of Chemistry 2008, 1, 693-717.

12. Rajasekhar, K.K.; Shankar, V.A.; Nithiyananthan, T.S.; Hareesh, G.; Naveen, P. Novel 1, 3, 4 - thiadiazole derivatives synthesis by MAOS. International Journal of ChemTech Research 2010, 2, 592-597.

13. Kanwar, S.; Mehta, D.D.; Das, R. Greener approach as a recent advancement in the synthesis of thiadiazole. International Journal of Pharmaceutical Sciences Review and Research 2015, 33, 140-147.

14. Hu, Y.; Li, C.-Y.; Wang, X.-M.; Yang, Y.-H.; Zhu, H.-L. 1,3,4-Thiadiazole: Synthesis, Reactions, and Applications in Medicinal, Agricultural, and Materials Chemistry. Chemical Reviews 2014, 114, 5572-5610, https://doi.org/10.1021/cr400131u.

15. Annapratima, G.N.; Pramod, A.G.; Shailee, V.T.; Jaiprakash, N.S.; Manoj, G.D. Ultrasound Promoted Green Synthesis, Docking Study of Indole Spliced Thiadiazole, \&\#945;-amino Phosphonates as Anticancer Agents and Antityrosinase Agents. Anticancer Agents in Medicinal Chemistry 2018, 18, 1267-1280, https://doi.org/10.2174/1871520618666180417163226.

16. Athawale, S.; Vijay, H.; Masand, E.; Subodh, B. Eco-Friendly Synthesize, and Biological Evaluation of 2 amino 5 substituted- 1,3,4-thiadiazoles. Research Journal of Chemical sciences 2016, 6, 40-43.

17. Salunkhe, N. Green synthesis, characterization and biological evaluation of some triazole and thiadiazole. Journal of Current Chemical \& Pharmaceutical Sciences 2013, 2, 100-106.

18. Nayak, A.S.; Madhava, N.V. Rapid synthesis and antimicrobial activity of some new 2-amino-5-alkyl/aryl1,3,4-thiadiazoles. Acta Chim. Pharm. Indica. 2014, 4, 63-67.

19. Siddiqui, I.R.; Nazaan, J. Novel 1,3,4 thiadiazole derivatives synthesis by MAOS. International Journal of Scientific and Research Publications 2014, 4, 1-8.

20. Haga, T.; Fujikawa, K.; Koyanag, T.; Nakajima, T.; Hayashi, K. Some New 2-Substituted 5Trifluoromethylpyridines. Heterocycles 1984, 22, 117-124.

21. Sangshetti, J.N.; Nagawade, R.R.; Shinde, D.B. Synthesis of novel 3-(1-(1-substituted piperidin-4-yl)-1H1,2,3-triazol-4-yl)-1,2,4-oxadiazol-5(4H)-one as antifungal agents. Bioorg Med Chem Lett 2009, 19, 35643567, https://doi.org/10.1016/j.bmcl.2009.04.134.

22. Kokila, P. A Simple and Efficient Procedure for Synthesis of Biologically Active1,2,4-Triazolo-[3,4-b]1,3,4-thiadiazole-2-aryl-thiazolidine 4-one Derivative. Researchjournal of chemical sciences 2011, 1, 1826.

23. Kushwaha, N.; Swatantra K. Biological Activities of Thiadiazole Derivative.International Journal of Chemtech Research. 2012, 4, 517-531. 
24. Richardson, K.; Barmmer, W.; Marriott, M.S.; Troke, P.F. Activity of UK-49,858, a Bis-Triazole Derivative, Against Experimental Infections with Candida albicans and Trichophyton mentagrophytes. Antimicrobial Agents and Chemotherapy 1985, 27, 832-835, https://doi.org/10.1128/aac.27.5.832.

25. Kumar, S. Thiadiazoles: Progress Report on BiologicalActivities. Der Pharma Chemica 2011, 3, 330-341.

26. Kharb, R.; Kau, P. Significance of thiadiazole derivatives as antimicrobial agents. International journal of Research in Pharmaceutical and Biomedical sciences 2011, 2, 1520-1540.

27. Varandas, L.S.; Fraga, C.A.M.; Miranda, A.L.P.; Barreiro, E.J. Design, Synthesis and Pharmacological Evaluation of New Nonsteroidal Antiinflammatory 1,3,4-Thiadiazole Derivatives. Letters in Drug Design \& Discovery 2005, 2, 62-67, https://doi.org/10.2174/1570180053398235,

28. Mohd, A. Synthesis pharamaceutically important 1,3,4 thiadiazole and imidazolione derivativesas antimicrobials. Indian journal of chemistry 2009, 48B, 1288-1293.

29. Hashem, E.H.; Bakr, M.A. New 1,3,4-Thiadiazole Derivatives: Synthesis, Characterization, and Antimicrobial Activity. Journal of heterocyclic chemistry 2019, 56, 1038-1047.

30. Mahmoud, H.K.; Abbas, A.; Gomh, M.S. Synthesis, Antimicrobial Evaluation and Molecular Docking of New Functionalized Bis(1,3,4-Thiadiazole) and Bis(Thiazole) Derivatives. Polycyclic aromatic compounds 2020, https://doi.org/10406638.2019.1709085.

31. Gur Mahmut. Synthesis, Characterization, and Antimicrobial Properties of New 1,3,4-Thiadiazoles Derived from Azo Dyes. Journal of Heterocyclic Chemistry, 2019, 56, 980-987.

32. Moustafa A.H.; Ahmed, H.D.; Wssimy, E.M.; Mohamed A.F.M. Synthesis, antimicrobial studies, and molecular docking of some new dihydro-1,3,4-thiadiazole and pyrazole derivatives derived from dithiocarbazates. An International Journal for Rapid Communication of Synthetic Organic Chemistry 2020, 2020,1843179. https://doi.org/10.1080/00397911.

33. Azimullah, M.J.;Nagesh, Khadri.; Bushra, B. M.; Sunil, K.; Shaukath, A.K. Synthesis, docking and biological evaluation of thiadiazole and oxadiazole derivatives as antimicrobial and antioxidant agents.Results in Chemistry 2020, 2, 994-999. 